\title{
Empirical Research on the Influence of Organizational Support on Psychological Capital
}

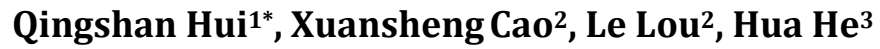 \\ ${ }^{1}$ Research Center of Manufacturing Enterprises Management Innovation, \\ Guangdong University of Technology, Guangzhou, China \\ ${ }^{2}$ Guangdong University of Technology, Guangzhou, China \\ ${ }^{3}$ Institute of Management Decision, Guangdong Social Sciences Academy, Guangzhou, China \\ Email: ${ }^{\text {mssgd@163.com }}$
}

Received 20 February 2014; revised 20 March 2014; accepted 27 March 2014

Copyright (C) 2014 by authors and Scientific Research Publishing Inc.

This work is licensed under the Creative Commons Attribution International License (CC BY). http://creativecommons.org/licenses/by/4.0/

(c) () Open Access

\begin{abstract}
Psychological capital is an individual's positive psychological state of development, which has four features and five criteria. Psychological capital structure in Chinese cultural context contains: calm, hope, optimism and confidence. On the basis of researching literature, the recoveries of the questionnaire were analyzed by applying Structural Equation Model (SEM). The study found that perceived organizational support has a positive impact on the 4 dimensions of psychological capital (calm, hope, optimism and self-confidence).
\end{abstract}

\section{Keywords}

Psychological Capital, Organizational Support, Structural Equation Model (SEM)

\section{Introduction}

Psychological capital (also known as the positive psychological capital) is relatively a new concept in the field of organizational behavior, which was put forward for the first time in 2004 by Fred Luthans, a professor of organizational behavior in the University of Nebraska-Lincoln and former President of Academy of Management magazine. And it refers to the individual state of a positive psychological development. Psychological capital is different from the economic capital, social capital and human capital. Economic capital answers the question of "What do you have", including the capital, assets, equipment, patents, data, etc. Social capital answers the ques-

${ }^{*}$ Corresponding author.

How to cite this paper: Hui, Q.S., et al. (2014) Empirical Research on the Influence of Organizational Support on Psychological Capital. American Journal of Industrial and Business Management, 4, 182-189.

http://dx.doi.org/10.4236/ajibm.2014.44025 
tion of "who do you know", including relationships, friends, contact network, etc.; Human capital answers the question of "what do you know", including experience, education, skills, knowledge, idea, etc.; The psychological capital answers the question of "who are you”, including faith, hope, optimism, toughness, etc. [1]. Fred Luthans, Carolyn M. Youssef and some other people also pointed out that the standards of determining whether a resource can form competitive advantage include: long term, namely whether the resource can form a lasting competitive advantage and has a long life, rather than a flash in the pan; Uniqueness, namely something that only you have, other organizations do not; cumulative, namely the resources can continuously increase the competitive advantage for the organization; inter-connectivity, namely each component works together to form the overall competitive advantage; renewal, namely the resources can be constantly updated and added. Economic capital can form competitive advantage only in the aspect of cumulative, but it could not form a clear advantage in other ways. The human capital has an advantage in the aspect of cumulative and the advantage is uncertain in other aspects. Social capital has advantages in the aspects of uniqueness, cumulative and inter-connectivity, but its advantages in such aspects as long term and renewal are not obvious. Only the psychological capital having the all above five aspects can form a significant competitive advantage [1].

Psychological capital research originates from the positive psychology movement. The positive psychology movement was advocated by the former American psychological association chairman Seligman. Martin E. P. in 2000 proposed that psychology and behavior science should pay more attention to guide and promote the positive aspects of human life, and not just to treat mental illness. What positive psychology concerns include: benefits, satisfaction, hope and happiness, courage, interpersonal skills, aesthetic, persistence, forgiveness, creativity, consciousness of the future, potential and wisdom, civic virtue, responsibility, altruism, tolerance, professional ethics, manners, etc. [2]. American Psychologist magazine respectively published two special issues devoted to positive psychology problems in January 2000 and March 2001 [3] [4]. In the 2001 winter volumes of Journal of Humanistic Psychology, there are 6 articles talking about positive psychology [5]. In addition, Coutu D. L., Hamel G., Klonhlen E. A. and other scholars respectively studied the related problems in positive psychology [6]-[14]. Positive psychology has become a new development direction in psychological science and behavioral science research in the new century [15].

The idea of positive psychology has triggered the research of positive organizational behavior. Inspired by the idea of positive psychology, Fred Luthans came up with the concept of positive organizational behavior (POB) for the first time in 2002, and define it as "the research and application of the human resources superiority and psychological ability, which are measurable, evolvable and have a significant effect on the performance”. He also put forward the CHOSE model related to the core contents, namely the core content of positive organizational behavior includes confidence, hope, optimism, subjective well-being and emotional intelligence [16]. In the same year, Fred further put forward five standards defining the POB extension [17]. The positive organization research center at the University of Michigan, which studies specifically for positive organizational scholarship (POS), pointed out in their books that the POS core concepts include: process, ability, structure, motivation, output or result, etc. [18]. The guiding ideology of POS and POB is consistent, and both of them research the organizational behavior and performance problems from the positive sides. In addition, Wright T. A., Erez A. and other scholars also studied the positive organizational behavior [19] [20].

\section{Literature Research}

Predecessors' research achievements about the psychological capital include psychological capital concept, the relationship between psychological capital and performance, etc.

Fred Luthans, James B Avery and other scholars in 2006 defined psychological capital as: individual positive psychological state of development, it has four features and five criteria. The four characteristics: 1) have confidence in the challenging work and try to complete it; 2) treat the present and the future optimistically; 3)face the future, set goals and take steps to achieve goals; 4) be able to recover from adversity or frustration and continue until succeed. The five judgment standards include: 1) they are based on theory and research; 2) can effectively measure; 3) is relatively new and unique in the field of organizational behavior ; 4) is a kind of changeable state of mind (not fixed psychological traits); 5) has a positive influence on work performance [21]. On the basis of generalization and summarization of research achievements of positive organizational behavior, Fred Luthans in 2004, Carolyn M. Youssef in 2008 put forward that psychological capital structure included four aspects, namely: 1) Confidence or self-efficacy. Albert Bandura defined self-efficacy as that an individual mobilize the motivation and cognitive resources in a particular context, take the necessary actions to complete a specific task. 
High confidence people choose challenging work and make efforts to finish it. 2) Hope. C. Rick Snyder who is a positive psychologist pointed out that hope is a state of motivation formed by the interaction of goals, agency and pathways. Individuals with high sense of hope think they are capable and are willing to choose the appropriate way to achieve their goals. 3) Optimism. Individual adopts the positive method to explain the intrinsic, ancient, common events, and explain outward, temporary and situational event in a negative way. Optimists treat what happens in life positively, they seldom have such negative moods as depression, guilt and remorse. 4) Resiliency. Individual's ability of getting out of adversity, failure, uncertainty and recovering from them. Restoring force includes three aspects: accept the reality that, consider life as positive, adapt to environmental changes [22].

The study led by Gallup Leadership Institute of university of Nebraska_Lincoln in America in 2006 found that psychological capital has significant positive correlation with employees' performance and job satisfaction; employee's work performance can be improved by the psychological capital training [23]. Luthans, Avery and Avolio in 2006 have found that the rate of return on investment of psychological capital can be as high as $270 \%$ through intervention studies [21]. With the help of psychological capital scale (include three indicators: hope, optimism and resilience), which is developed by Fred Luthans, Fred Luthans, Bruce J Avolio, Fred O Walumbwa, Weixing Li in 2005 took Chinese employees as samples to study the relationship between psychological capital and performance and found that the psychological capital and work performance (include the executive director's evaluation and pay for performance) were significantly positive correlated [24]. Luthans Kyle W., Jensen, Susan M. in 2005 studied the relationship between nurses' psychological capital and work performance, the results showed that the psychological capital has significant positive correlation with the intention to stay ,the targets of the unit and work commitment [25]. Susan M. Jensen, Fred Luthans and others in 2006 found through research that the leaders' psychological capital was positively correlated with employees' cognition of leaders' integrity [26]. Zhong Li-feng in 2007 found that the three dimensions of psychological capital (hope, optimism, resilience) have a positive influence on job performance, organizational commitment and organizational citizenship behavior [27]. The author in 2009 found through research that, under the background of Chinese culture, psychological capital structure include: calm, hope, optimism, confidence [28].

Perceived organizational support (POS), which is proposed by the American social psychologist Robert Eisenberger , points out the employee's perception and concerns about how the groups consider their contributions and care about their interests, namely the groups' supports that employees feel. If employees feel that their organization support their work very much, then they may feel psychologically comfortable and be willing to make more contribution to organization.

\section{The Research Hypothesis}

Because psychological capital is individual staff's positive psychological state related to work, therefore, organizational factors also may have effect on psychological capital. Here we choose perceived organizational support as influencing factors to study organizational factors' influence on psychological capital. Research hypotheses are as follows:

Hypothesis 1: Perceived organizational support has a positive influence on calm.

Hypothesis 2: Perceived organizational support has a positive influence on hope.

Hypothesis 3: Perceived organizational support has a positive effect on optimism.

Hypothesis 4: Perceived organizational support has a positive effect on confidence.

Hypothesis model is showed in Figure 1.

\section{The Research Methods and Tools}

\subsection{Research Method}

We use the method of exploratory factor analysis and path analysis of structural equation, and use the software of SPSS13.0 and AMOS4.0.

The method of path analysis of structural equation, also called structure model, is used to analyze causal relationship between variables. The similarity of path analysis method and the traditional regression analysis method is that they can both analyze the relationship between independent variable and dependent variable, but there are obvious differences between them (Wu Ming-long, 2007).

1) In the regression analysis model, variables are only divided into the independent variables and dependent 


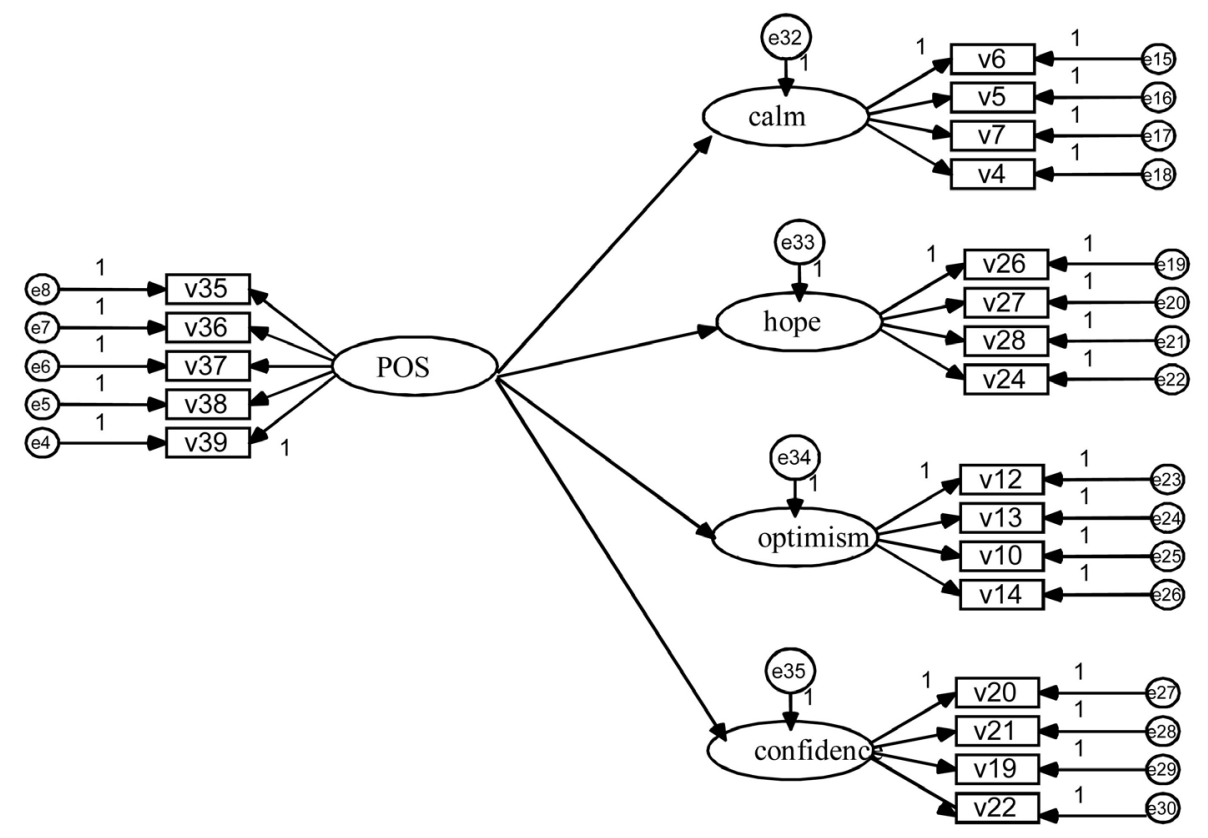

Figure 1. The hypothesis model diagram of organizational support's influence on the psychological capital.

variables, and these variables are all observed variables without error, but in a path analysis model, the independent variable and dependent variable can be observed variables without error, can be latent variables with error as well and model analyzing the relation between latent variable is called path analysis with latent variables (PALV for short). Therefore, residual error in path analysis model is more complex than it in the regression model.

2) In regression analysis model, after the dependent variables are explained by the independent variables, the residual errors are assumed to have nothing to do with the independent variables, while in path analysis model, the residual errors are allowed to associate with variables.

In addition, path analysis technology can use multiple indexes to test the fitting degree of the whole model, but the regression analysis model use only a handful of indicators to test. It is just because of the above characteristics of path analysis, it is widely used in psychology and behavioral science research.

Variables used in this study are all latent variables, therefore, we use path analysis method of SEM to modeling and analysis.

\subsection{The Sample Conditions}

1800 questionnaires were sent to Guangdong, Shanghai, Beijing, Henan, Guangxi, Zhejiang, Anhui, Sichuan, Chongqing, Yunnan and other provinces and cities, and 1574 effective questionnaires were retrieved back. The effective recovery rate was $87.4 \%$. We take gender, age, years of working, education background, the nature of the department, post of duty, technical titles as investigation contents.

\subsection{The Questionnaires Used and Test of Them}

Questionnaire developed by the author in 2009 was used to test psychological capital, and it is composed of 16 items. The results of factor analysis and reliability test are shown in Table 1 . Perceived organizational support questionnaire, developed by Ling Wen-quan, Yang Hai-jun in 2006, was used to test the organizational support. It selects five dimensions of the support projects, the survey data collected was used for factor analysis and reliability test, the results are shown in Table 2. The analysis result shows that the perceived organizational support questionnaire meet the demands of psychometrics, and has good reliability.

\section{The Results of the Study and Discussion}

The standard solution of the influence of organizational support on psychological capital is shown in Figure 2. 
Table 1. The questionnaire results of psychological capital $(\mathrm{N}=1574)$.

\begin{tabular}{|c|c|c|c|c|c|}
\hline \multirow{2}{*}{ Project } & \multicolumn{4}{|c|}{ factor } & \multirow[b]{2}{*}{ Common degree } \\
\hline & Calm & Hope & Optimism & Confidence & \\
\hline V6 I can overcome the bad emotions in the work, and maintain it stable. & 0.812 & & & & 0.732 \\
\hline V5 I can adjust my own negative emotions quickly in the work. & 0.797 & & & & 0.713 \\
\hline V7 I can face danger fearlessly in the work. & 0.726 & & & & 0.633 \\
\hline V4 I can calm in the face of difficulties. & 0.659 & & & & 0.554 \\
\hline V26 I have clear goals of work. & & 0.771 & & & 0.705 \\
\hline V27 I have the patience to achieve the work objectives. & & 0.765 & & & 0.704 \\
\hline V28 I am working with enthusiasm. & & 0.719 & & & 0.633 \\
\hline V24 I am full of hope for the future work. & & 0.680 & & & 0.610 \\
\hline V12 For work, I can always see the good aspects. & & & 0.774 & & 0.661 \\
\hline V13 I think the work usually produces good result. & & & 0.744 & & 0.658 \\
\hline V10 I always feel that the good thing is more than the bad in the work. & & & 0.737 & & 0.591 \\
\hline V14 I always believe that I don't need pessimistic in the work. & & & 0.556 & & 0.533 \\
\hline V20 I believe I can communicate with colleagues and external people well. & & & & 0.746 & 0.644 \\
\hline V21 I am confident to discuss my work in the meeting. & & & & 0.726 & 0.676 \\
\hline V19 I believe I can participate in the discussion of company affairs well. & & & & 0.726 & 0.614 \\
\hline V22 I believe I can find the better solution to solve the problems in the work. & & & & 0.610 & 0.548 \\
\hline Rate of variance explained (\%) & 40.567 & 8.775 & 7.660 & 6.803 & \\
\hline The overall rate of variance explained & & & & $804 \%$ & \\
\hline Cronbach a rate of variance explained & & & & .889 & \\
\hline
\end{tabular}

Table 2. The questionnaire results of POS $(\mathrm{N}=1574)$.

\begin{tabular}{ccc}
\hline Project of the questionnaire & Factor loading Common degree \\
\hline Our organization agrees with employees' reasonable requirements of changing the working confidence. & 0.851 & 0.620 \\
Our organization will give you a hand when you are in trouble. & 0.848 & 0.632 \\
Our organization let our employees play the appropriate role. & 0.828 & 0.725 \\
Our organization can make the employees' work interesting. & 0.795 & 0.686 \\
Our organization can help employees to develop their potential ability. & 0.788 & 0.720 \\
The cumulative variance explained & $67.636 \%$ \\
Cronbach a coefficient & 0.880
\end{tabular}

The fitting degree indexes of the model are shown in Tables 3-5. As we can see from the figure and table, the conception model of organizational support's influence on psychological capital fit the actual data very well. The standardized coefficients of organizational support's influence path to psychological capital are shown in Table 6. Data analysis results show that organizational support has significant positive influence on the four aspects of psychological capital, and the degree of influence is very high. If employees feel that the organization is supportive for their work, they will: setting up clear goals, and taking various measures to achieve work target, being full of hope to job prospects; they tend to explain the incidents in work in a positive way, and think it is just a temporary phenomenon even when they encounter difficulties and setbacks. They will believe the sky will be clearer after the rain, they often keep the stable mood, do things firmly and calmly, they have great confidence in their work, and believe they can finish the work very well. On the other hand, if employees feel that organization does not support their work or the support is not enough, then employees may show negatively. They not only have no confidence in their work and muddle along, but also have no clear work target and be lacking in initiative and be irritable, etc. Through inspection, our research hypothesis 1, 2, 3, 4 in this part are all valid. We can see from Table 6, organizational support has an obvious effect on employees’ psychological capital, therefore, a good organization atmosphere, service management is very necessary.

The existing research suggests that POS has influence on many aspects, such as organizational commitment 


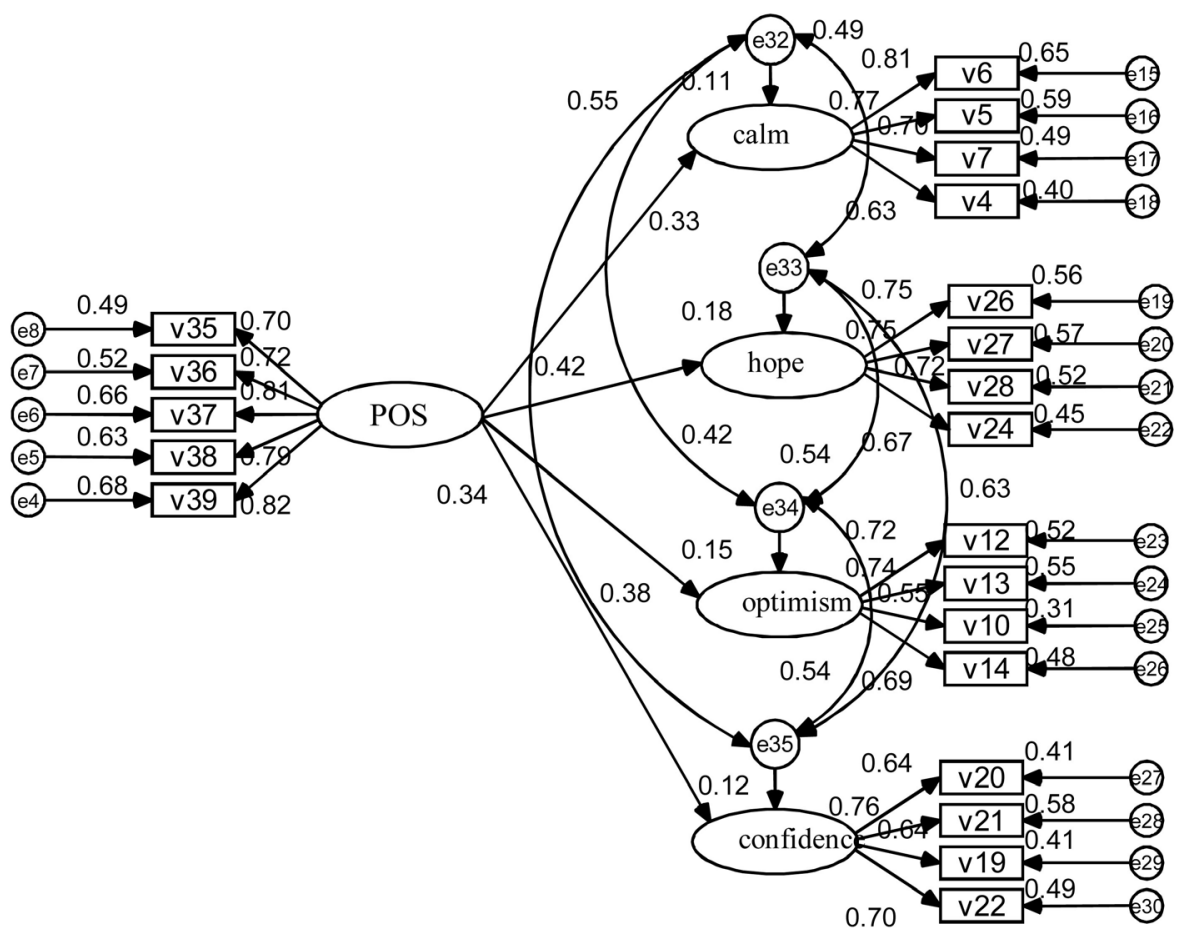

Figure 2. A schematic diagram showing the influence of standard solution of organizational support on psychological capital.

Table 3. The absolute fitting degree index of the structure model that the influence of organizational support on psychological capital.

\begin{tabular}{cccc}
\hline GFI & AGFI & RMR & RMSEA \\
\hline 0.952 & 0.938 & 0.041 & 0.047 \\
\hline
\end{tabular}

Table 4. The appreciation fitting degree index of the structure model that the influence of organizational support on psychological capital.

\begin{tabular}{ccccc}
\hline NFI & RFI & IFI & TLI & CFI \\
\hline 0.943 & 0.933 & 0.955 & 0.947 & 0.955 \\
\hline
\end{tabular}

Table 5. The brief fitting degree index of the structure model that the influence of organizational support on psychological capital.

\begin{tabular}{cccc}
\hline PGFI & PNFI & CN & NC \\
\hline 0.738 & 0.804 & 417 & 4.461 \\
\hline
\end{tabular}

Table 6. The standard coefficient table of the organizational support's effect of path on psychological capital.

\begin{tabular}{ccccc}
\hline Path direction & Non Standardized estimate & Standardized error & Value of T & Standardized estimate \\
\hline calm<---POS & 0.271 & 0.024 & $11.148^{* * *}$ & 0.326 \\
hope $<-$-POS & 0.333 & 0.024 & $13.977^{* * *}$ & 0.418 \\
optimism<---POS & 0.285 & 0.023 & $12.402^{* * *}$ & 0.381 \\
confidence<---POS & 0.217 & 0.020 & $10.710^{* * *}$ & 0.340
\end{tabular}

Note: ${ }^{* * *}$ stands for $\mathrm{p}<0.001$.

and altruistic behavior and so on. Shore and Tetrick think that POS can reduce the occurrence of continuance commitment of organizational commitment. George and Brief think that POS can be contributed to the extra role 
behavior, it includes helping organization to avoid risks, putting forward some constructive suggestions and getting skills and knowledge which is good for organization. Eisenberger's research of 2001 suggests that POS has a great influence on organizational commitment. Ling Wen-quan and Yang Hai-jun find that POS and emotional commitment has a strong positive correlation, it may play a role in predicting the altruistic behavior of employees. There are not organizations getting the achievement which POS has found, so in this sense, our research improves the POS and psychological capital theory system.

\section{References}

[1] Luthans, F., Luthans, K.W. and Luthans, B.C. (2004) Positive Psychological Capital: Beyond Human and Social Capital. Business Horizons, 47, 45-50.

[2] Seligman, M.E.P. and Csikszentmihalyi, M. (2000) Positive Psychology: An Introduction. American Psychologist, 55, 5-14.

[3] Martin, E.P.S. and Fausto, M. (2000) American Psychologist, 55.

[4] Kennon, M.S., Barbara, L.F. (2001) American Psychologist, 56.

[5] Rich, G.J., Taylor, E. (2001) Journal of Humanistic Psychology, 41.

[6] Coutu, D.L. (2002) How Resilience Works. Harvard Business Review, 80, 46-55.

[7] Hamel, G. and Välikangas, L. (2003) The Quest for Resilience. Harvard Business Review, 81, 52-63.

[8] Harms, P.D. and Luthans, F. (2012) Measuring Implicit Psychological Constructs in Organizational Behavior: An Example Using Psychological Capital. Journal of Organizational Behavior, 33, 589-594.

[9] Horne III, J. and Orr, J. (1998) Assessing Behaviors That Create Resilient Organizations. Employment Relations Today, 24, 29-39.

[10] Klonhlen, E.C. (1996) Conceptual Analysis and Measurement of the Context of Ego Resiliency. Journal of Personality and Social Psychology, 70, 1067-1079.

[11] Block, J. and Kremau, A.M. (1996) IQ and Ego Resiliency: Conceptual and Empirical Connections and Separateness. Journal of Personality and Social Psychology, 70, 349-361.

[12] Stajkovic, A.D. and Luthans, F. (1998) Self-Efficacy and Work-Related Performance: A Meta-Analysis. Psychological Bulletin, 124, 240-261.

[13] Sympson, S.C., Ybasco, F.C., Borders, T.F., Babyak, M.A. and Higgins, R.L. (1996) Development and Validation of the State Hope Scale. Journal of Personality and Social Psychology, 70, 321-335.

[14] Magaletta, P.R. and Oliver, J.M. (1999) The Hope Construct, Will and Ways: Their Relations with Self-Efficacy, Optimism, and Well-Being. Journal of Clinical Psychology, 55, 539-551.

[15] Memili, E., Welsh, D.H.B. and Luthans, F. (2013) Going Beyond Research on Goal Setting: A Proposed Role for Organizational Psychological Capital of Family Firms. Entrepreneurship Theory and Practice, 37, 1289-1296.

[16] Luthans, F. and Jensen, S.M. (2002) Hope: A New Positive Strength for Human Resource Development. Human Resource Development Review, 1, 304-322.

[17] Li, J.Z., Wang, W.Z. and Shi, J.N. (2003) Positive Psychology: A New Research Direction. Advances in Psychological Science, 11, 321-327.

[18] Luthans, F. (2002) Positive Organizational Behavior: Developing and Managing Psychological Strengths. Academy of Management Executive, 1, 57-75.

[19] Luthans, F. (2002) The Need for and Meaning of Positive Organizational Behavior. Journal of Organizational Behavior, 23, 695-706.

[20] Cameron, K., Dutton, J. and Quinn, R.E. (2003) Positive Organizational Scholarship: Foundations of a New Discipline. Hardcover, Berrett-Koehler Publishers, Inc., San Francisco.

[21] Wright, T.A. (2003) Positive Organizational Behavior: An Idea Whose Time Has Truly Come. Journal of Organizational Behavior, 24, 437-442.

[22] Erez, A. and Isen, A.M. (2002) The Influence of Positive Affect on the Components of Expectancy Motivation. Journal of Applied Psychology, 87, 1055-1067.

[23] Luthans, F., Avey, J.B., Avolio, B.J., Norman, S.M. and Combs, G.M. (2006) Psychological Capital Development: Toward a Micro-Intervention. Journal of Organizational Behavior, 27, 387-393.

[24] Luthans, F. and Youssef, C.M. (2004) Human, Social, and Now Positive Psychological Capital Management: Investing in People for Competitive Advantage. Organizational Dynamics, 33, 143-160. 
[25] Gallup Leadership Institute. Psychological Capital: Measurement and Relationship with Performance and Satisfaction. http://gli.unl.edu/uploads/psycapbriefing.pdf

[26] Luthans, F., Avolio, B.J., Walumbwa, F.O. and Li, W.X. (2005) The Psychological Capital of Chinese Workers: Exploring the Relationship with Performance. Management and Organization Review, 1, 249-271.

[27] Chen, D.J.Q. and Lim, V.K.G. (2012) Strength in Adversity: The Influence of Psychological Capital on Job Search. Journal of Organizational Behavior, 33, 811-839.

[28] Luthans, K.W. and Jensen, S.M. (2005) The Linkage between Psychological Capital and Commitment to Organizational Mission: A Study of Nurses. Journal of Nursing Administration, 35, 304-310. 